\title{
A Comparative Study of Assessment of Renal Stones Using USG and CT scan
}

\author{
G Rajesh $^{1}$, Waseem Akhtar ${ }^{2}$ \\ ${ }^{1}$ Associate Professor, Department of Radiology, FH Medical College, Tundla, ${ }^{2}$ Assistant Professor, Department of Radiology, FH Medical College, Tundla.
}

\section{Abstract}

Background: Renal stones, or nephrolithiasis, are a common problem worldwide. The present study was conducted to compare USG and CT scan in diagnosis of renal stones. Subjects and Methods: The present study was conducted on 76 cases of renal stones of both genders. USG Scan with Aloka SSD-500 with frequency convex probe, and Honda SSD-500 with frequency (3.5 MHz) convex probe was taken. Nonenhanced helical CT examinations were performed with an Elscint Helicat II scanner. Results: Out of 76 patients, males were 44 and females were 32. Age group 11-20 years had 12 patients, 21-30 had 24, 31-40 years had 35, 41-50 had 3 and $>50$ years had 2 patients. Types of stones were calcium oxalate in 43 , calcium phosphate in 8 , cystine in 21 and uric acid in 4 . The difference was significant $(\mathrm{P}<0.05)$. Out of 76 renal stones, USG diagnosed 61 positive and 3 negative while, CT diagnosed 59 positive and 5 negative. Sensitivity of CT scan found to be $95 \%$ and USG showed $92 \%$. Specificity of USG was $91 \%$ and CT was $87 \%$. Conclusion: Both imaging modalities found to be effective in diagnosing renal stones. However, USG resulted in better results and hence CT should be considered if USG is not present.

Keywords: CT scan, Renal stones, Ultrasonography.

Corresponding Author: Dr. Waseem Akhtar, Assistant Professor, Department of Radiology, FH Medical College, Tundla.

Received: June 2019

Accepted: June 2019

\section{Introduction}

Renal stones, or nephrolithiasis, are a common problem worldwide. With its increasing prevalence, they are imposing a significant economic burden for both developing and developed nations. The occurrence of renal stone is usually believed to be due to crystallization of minerals inside urine, which act as the nidus for more sedimentation and finally the formation of a stone within the kidney. ${ }^{[1]}$ Calculi are due to abnormal collection of certain chemicals like oxalate, phosphate and uric acid. These calculi can be present in kidney, urethra or in urinary bladder. Most of the previous study in diagnosis of renal calculi spots out the presence or absence of the calculi in the kidney. In this paper we propose an algorithm to detect the renal calculi and to find the size of the calculi. It is more helpful to change the diet conditions. ${ }^{[2]}$

Ultrasonography (US) is an accessible, relatively inexpensive imaging method that comes without the risks of exposure to ionizing radiation entailed by CT. Denton et al, ${ }^{[3]}$ reported the ability to detect stones as small as $2 \mathrm{~mm}$ using US imaging in a porcine model more than 30 years ago. With an ability to demonstrate radiopaque and radiolucent stones, hydronephrosis, renal inflammation, ruptured fornices, ureteric jets and resistive index, US can provide valuable clinical information. ${ }^{[4]}$ Despite the wider availability of US units and increased bedside utilization, the national usage of US for renal colic had not significantly changed from 2000 to 2008, although the use of CT scans has increased dramatically.5 The size and location of the stone and the overall health of the kidney can be assessed by CT scan and also by density of the stone in HU value by which the chemical composition of the stone can be predicted.6 The present study was conducted to compare USG and CT scan in diagnosis of renal stones.

\section{Subjects and Methods}

The present study was conducted in the department of Radiodiagnosis. It comprised of 76 cases of renal stones of both genders. All patients were informed regarding the study and written consent was taken. Ethical clearance was obtained before starting the study from institutional ethical committee.

General information such as name, age, gender etc. was recorded. A thorough clinical examination was done in all patients. USG Scan with Aloka SSD-500 with frequency convex probe, and Honda SSD-500 with frequency (3.5 $\mathrm{MHz}$ ) convex probe was taken. Similarly, Non-enhanced helical CT examinations were performed with an Elscint Helicat II scanner. Results thus obtained were subjected to statistical analysis. $\mathrm{P}$ value less than 0.05 was considered significant.

\section{Results}


Table 1: Distribution of patients

\begin{tabular}{|l|l|l|}
\hline \multicolumn{2}{|l|}{ Total- 76 } \\
\hline Gender & Males & Females \\
\hline Number & 44 & 32 \\
\hline
\end{tabular}

[Table 1] shows that out of 76 patients, males were 44 and females were 32 .

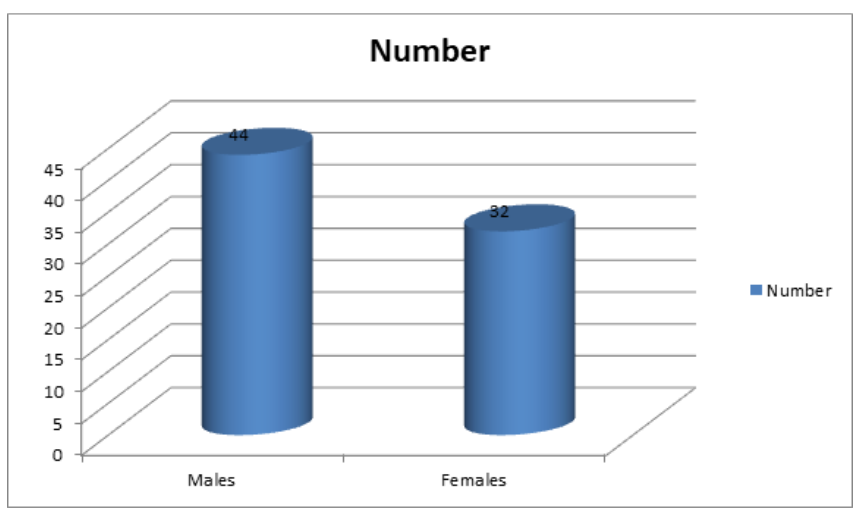

Figure 1: Distribution of patients

Table 2: Age wise distribution of cases
\begin{tabular}{|l|l|l|}
\hline Age group (Years) & Number & P value \\
\hline $11-20$ & 12 & \multirow{2}{*}{0.01} \\
\hline $21-30$ & 24 & \\
\hline $31-40$ & 35 & \\
\hline $41-50$ & 3 & \\
\hline$>50$ & 2 & \\
\hline
\end{tabular}

[Table 2, Figure 2] shows that age group 11-20 years had 12 patients, 21-30 had 24, 31-40 years had 35, 41-50 had 3 and $>50$ years had 2 patients. The difference was significant $(\mathrm{P}<$ $0.05)$.

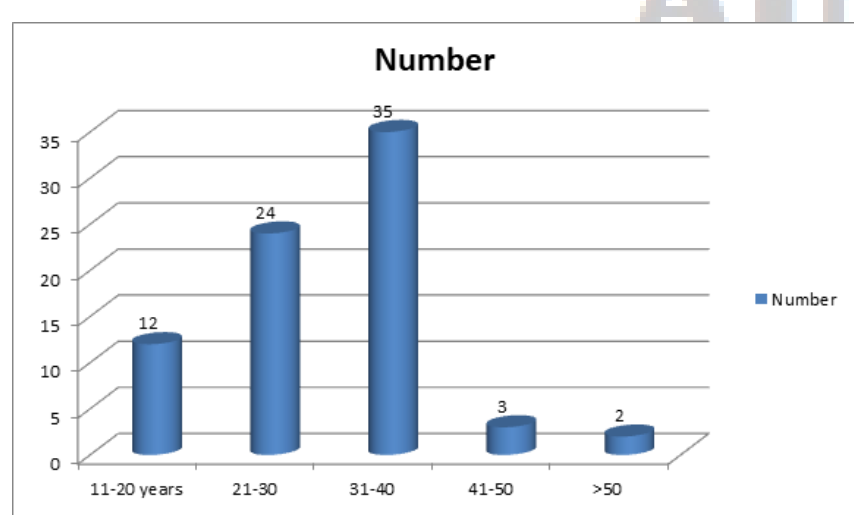

Figure 2: Age wise distribution of cases

\begin{tabular}{l}
\hline Table 3: Frequency of type of stones \\
\begin{tabular}{|l|l|l|}
\hline Type & Number & \multirow{2}{*}{ P value } \\
\hline Calcium oxalate & 43 & \\
\hline Calcium phosphate & 8 & \\
\cline { 1 - 2 } Cystine & 21 & \\
\cline { 1 - 2 } Uric acid & 4 & \\
\hline
\end{tabular}
\end{tabular}

[Table 3, Figure 3] shows that types of stones were calcium oxalate in 43 , calcium phosphate in 8 , cystine in 21 and uric acid in 4 . The difference was significant $(\mathrm{P}<0.05)$.

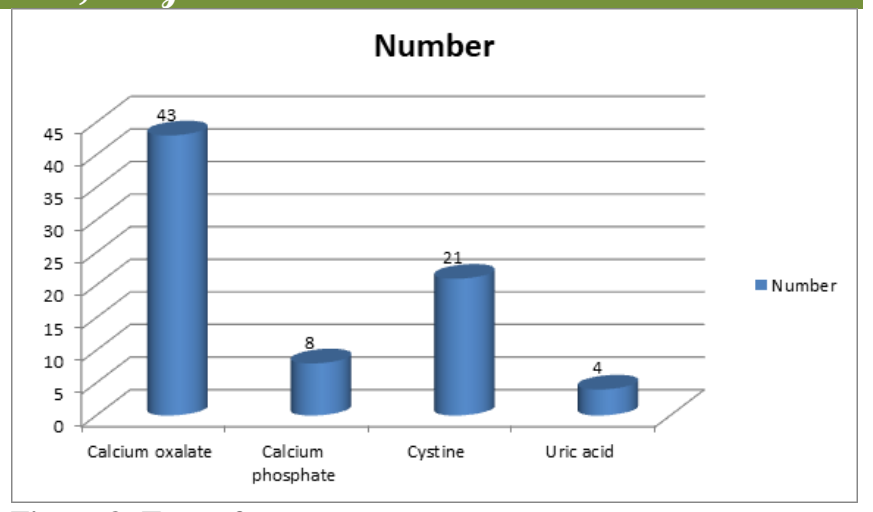

Figure 3: Type of stones

Table 4: Imaging with ultrasound and CT for detection of renal calculi

\begin{tabular}{|l|l|l|l|}
\hline USG & $\begin{array}{l}\text { Renal stones } \\
\text { present }\end{array}$ & $\begin{array}{l}\text { Renal stones } \\
\text { absent }\end{array}$ & Total \\
\hline $\begin{array}{l}\text { Positive for renal } \\
\text { stones }\end{array}$ & 61 & 1 & 62 \\
\hline $\begin{array}{l}\text { Negative for renal } \\
\text { stones }\end{array}$ & 3 & 11 & 14 \\
\hline Total & 64 & 12 & 76 \\
\hline CT & & 1 & 60 \\
\hline $\begin{array}{l}\text { Positive for renal } \\
\text { stones }\end{array}$ & 59 & 11 & 16 \\
\hline $\begin{array}{l}\text { Negative for renal } \\
\text { stones }\end{array}$ & 5 & 13 & 76 \\
\hline Total & 63 & & \\
\hline
\end{tabular}

[Table 4] shows that out of 76 renal stones, USG diagnosed 61 positive and 3 negative while, CT diagnosed 59 positive and 5 negative.

Table 5: Sensitivity and specificity of USG and CT scan for renal stones

\begin{tabular}{|l|l|l|}
\hline Parameters & USG & CT \\
\hline Sensitivity & $95 \%$ & $92 \%$ \\
\hline Specificity & $91 \%$ & $87 \%$ \\
\hline
\end{tabular}

[Table 5] shows that sensitivity of CT scan found to be $95 \%$ and USG showed $92 \%$. Specificity of USG was $91 \%$ and CT was $87 \%$.

\section{Discussion}

Renal stones, or nephrolithiasis, are a common problem worldwide. It has been observed that renal stones are associated with systemic diseases like Type 2 diabetes mellitus, obesity, dyslipidaemia, and hypertension. ${ }^{[7]}$ Lifestyle and environmental factors contribute significantlyin their formation. Presentation of renal colic is common and therefore treatment is not delayed

With its increasing prevalence, they are imposing a significant economic burden for both developing and developed nations. It has been observed that renal stones are associated with systemic diseases like Type 2 diabetes mellitus, obesity, dyslipidaemia, and hypertension. ${ }^{[8]}$ Lifestyle and environmental factors contribute significantly in their formation. Presentation of renal colic is common and therefore treatment is not delayed. However, in the absence of any preventive measures $>50 \%$ of renal stones 
may reoccur. ${ }^{[9]}$ The present study was conducted to compare USG and CT scan in diagnosis of renal stones.

In this study, out of 76 patients, males were 44 and females were 32. Age group 11-20 years had 12 patients, 21-30 had $24,31-40$ years had $35,41-50$ had 3 and $>50$ years had 2 patients. Bonigala et al, ${ }^{[10]}$ found that a total of 552 USG and CT examinations was done. Overall, the sensitivity and specificity of USG was 54 and $91 \%$, respectively. There was a significant association between sensitivity of US and stone size, but not with stone location $(\mathrm{P}=0.58)$. US significantly overestimated the size of stones in the $0-10$ $\mathrm{mm}$ range. Authors found that in 14\% (54/384) of cases where CT would suggest observation, US would lead to a recommendation for intervention. By contrast, when CT results would suggest intervention as management, US would suggest observation in $39 \%(65 / 168)$ of cases. An average of $22 \%(119 / 552)$ of patients could be inappropriately counselled.

We found that types of stones were calcium oxalate in 43 , calcium phosphate in 8, cystine in 21 and uric acid in 4 . Out of 76 renal stones, USG diagnosed 61 positive and 3 negative while, CT diagnosed 59 positive and 5 negative. The sensitivity of CT scan found to be $95 \%$ and USG showed $92 \%$. Specificity of USG was $91 \%$ and CT was $87 \%$.

It has been found that renal stones are common in obese and diabetic individuals. The recurrence rate of renal stones is high, with $50 \%$ recurring within 5 years of the initial stone event. The factors that determine the accelerating pace of stone formation in recurrent stone formers are not well known. Therefore, in any single stone former, one cannot predict which patient will relapse, however, the natural history of stone disease and the high rate of recurrence requires careful diagnostic evaluation and early treatment. $^{[11]}$

Erwin et al, ${ }^{[12]}$ found that all patients were prospectively defined as either positive or negative for ureterolithiasis, based on follow-up evaluation. 43 of the 62 patients were confirmed as havingureteral calculi based on stone recovery or urological interventions. US showed 93\% sensitivityand 95\% specificity in the diagnosis of ureterolithiasis; CT showed $91 \%$ and $95 \%$, respectively.

Pathology unrelated to urinary stone disease was demonstrated in six patients. Although bothmodalities were excellent for detecting ureteral stones, consideration of cost and radiation leadus to suggest that US be employed first and CT be reserved for when US is unavailable or nondiagnostic.

\section{Conclusion}

Authors suggested that both imaging modalities found to be effective in diagnosing renal stones. However, USG resulted in better results and hence CT should be considered if USG is not present.

\section{References}

1. Smith RC, Rosenfield AT, Chol KA. Acute flank pain: comparison of non-contrast-enhanced CT and intravenous urography. Radiology 1995;194:789-94.

2. Koelliker SL, Cronan JJ. Acute urinary tract obstruction. Imaging update. UrolClin North Am1997;24:571-83.

3. Denton ER, Mackenzie A, Greenwell T, Popert R, Rankin SC. Unenhanced helical CT for renal colic- is the radiation dose justifiable? ClinRadiol 1999; 54:444-7.

4. Sommer FG, Jeffrey RB, Rubin GD, Napel S, Rimmer SA, Benford J, et al. Detection of ureteral calculi in patients with suspected renal colic: value of reformatted noncontrast helical CT. AJR 1995;165: 509-14.

5. Vieweg J, Teh C, Freed K, Leder RA, Smith RHA, Nelson RH, et al. Unenhanced helical computerized tomography for the evaluation of patients with acute flank pain. J Urol 1998;160:679-84.

6. Wong-You-Cheong JJ, Wagner BJ, Davis CJ. Transitional cell carcinoma of the urinary tract.Radiologic-pathologic correlation. Radiographics 1998;18:123-42.

7. Dalla Palma L, Stacul F, Bazzocchi M, Pagnan L, Festini G, Marega D. Ultrasonography and plain film versus intravenous urography in ureteric colic. ClinRadiol 1993;47:333-6.

8. Cronan JJ, Tublin ME. Role of the resistive index in the evaluation of acute renal obstruction. AJR 1995;164:377-8.

9. Burge HJ, Middleton WD, McClennan BL. Ureteral jets in healthy subjects and in patientswith ureteral calculi: comparison with color Doppler US. Radiology 1991;180:437-42.

10. BonigalaPratap Kumar, S Ahmed Varusai. Evaluation of Renal Stones By Computed Tomography and its Correlation With Urine PH And Biochemical Analysis. Int. j. clin. biomed. res. 2018;4(1): 46-51.

11. Nakada SY, Hoff DG, Attai S, et al. Determination of stone composition by noncontrast spiral computed tomography in the clinical setting. Urology. 2000; 55:816-819.

12. Erwin BC, Carroll BA, Sommer FG. Renal colic: The role of ultrasound in initial evaluation. Radiology 1984;152:147-50.

Copyright: () the author(s), publisher. Asian Journal of Medical Radiological Research is an Official Publication of "Society for Health Care \& Research Development". It is an open-access article distributed under the terms of the Creative Commons Attribution Non-Commercial License, which permits unrestricted non-commercial use, distribution, and reproduction in any medium, provided the original work is properly cited.

How to cite this article: Rajesh G, Akhtar W. A Comparative Study of Assessment of Renal Stones Using USG and CT scan. Asian J. Med. Radiol. Res. 2019; 7(1):104-106.

DOI: dx.doi.org/10.21276/ajmrr.2019.7.1.23

Source of Support: Nil, Conflict of Interest: None declared. 